\title{
Construction and Thinking of Staff Training System on the Basis of Knowledge Management
}

\author{
Huixian Chen \\ Huanghe Science \& Technology College; Zhengzhou 450006, China
}

\begin{abstract}
With the advent of information era, knowledge management has been one of important content of enterprise management, and the staff training system of enterprise can be more optimized on the basis of this. The current staff training system in our country exists lots of deficiency, for example, the problem of backward training methods, mistaken training directions and lacking of assessment system. On the experience of knowledge management, the corresponding measures can be taken that changing the training method, scheduling rational staff training contents and objectives and perfecting the assessment system, in order to constantly perfect the staff training system of enterprise and realize the long-term development and constant promotion of personal quality of staffs.
\end{abstract}

Keywords: Knowledge management; staff training system; market economy.

\section{Introduction}

Since from the reform and opening-up policy, the social economy of our country has been developed rapidly, and especially after stepping into the century, the development method of social economy has been transformed and the era of economic globalization has been gradually come. In addition, the development rate has been faster and faster, and cultural knowledge has been one kind of new-type and very significant economy formation affecting the social economy. And cultural productivity will have more and more important effect on social economy.

\section{The Deficiency of Current Staff Training System of Enterprise in Our Country}

\subsection{Backward training method}

At present stage, quite a lot of enterprises in our country still have not formed a set of perfect and systematic staff training system, and the training method still exists very backward questions, even part of enterprises have not establish the relevant training department yet. In addition, most of enterprises still mainly take the method of traditional unilateral teaching of trainers when training with staffs, which is basically same with the traditional teaching method in the school, namely, teachers teach students unilaterally and students is passive to accept the knowledge so that students gradually lose the ability of initiatively exploring and positively thinking and the enthusiasm to study, which will become the more and more stiff study method. In enterprises, such training method has same effect on staffs, and they can only passively absorb the development concept and related knowledge delivered by trainers, but they cannot experience by themselves. And although such training can thoroughly deliver the training knowledge that staffs should learn to them, these knowledge cannot been well understood and absorbed by staffs due to the existing problems of method, as a result, perfect training effect cannot been created. What's more, the unilateral teaching of trainers will result in definitely lacking of necessary communication between the teacher and the learner, making trainers cannot understand the personal and work characteristic of each staff and their absorption and understanding condition with courses and cannot timely teach aiming at their personal actual situation, which will only make the whole training work go ahead stiffly but cannot produce the effect of practice should make. In addition, the trainers selected by part of enterprises also exists the problem of deficient management quality of enterprise, which will affect the effect of training to great degree. Therefore, enterprises should make the strict assessment with the enterprise management quality equipped with them when selecting trainers. 


\subsection{Mistaken training method}

In order to make long-term development and constantly be strong, one enterprise must have long-term development goal and cannot decide the content and goal only aiming at the immediate interests. However, there exists a big problem when large amounts of enterprises in our current country are training staffs. Many enterprise managers usually make up the related training contents and objectives according to the immediate interests when they are making training with staffs, driven by the short-term economic benefit rather than considering the long-term development of enterprises and the requirement of individual development of staffs. But the personal quality, work ability and attitude of staffs just are the key points to make progress of enterprise development, which decides the development direction of enterprise. And in this way, it only will make enterprises step into stuffy and stagnant state, which equals to make the rising space blocked, and if things go like this, it may make enterprises faced with the bad condition of running difficultly. In addition, many enterprises want to try their best to make the lest cost invest to change the biggest profit return. In order to reduce the invest of human resource, material resource and financial resource as much as possible, they didn't make the investigation and do the necessary market research work before taking the systematic staff training, as a result, they didn't get hang of the development direction of social economy and demand of market and personnel developing. And they only view from the current development condition of enterprises to formulate the related training contents and objectives, obviously, which is a kind of behavior lacking of long-term consideration. And in this way, neither of individual and enterprise will get the promotion they should have, so that enterprises will only acquire the temporary profit and cannot realize long-term development and prosperity. And the individual will have no way to give play to the actual benefit for enterprises because that they can't get promotion they should have, which will make it difficult for enterprises to find available resources when faced with difficulties. Individuals and enterprises will be dissatisfied with each other, which will only make the development of enterprises faced with bigger and bigger difficulties so that they cannot make long-term development.

\subsection{Lacking of assessment system}

Assessment system is crucial to the training work, and there still exists great problems in the staff training system of most enterprises in our current country. And when carrying out the training work, enterprise managers usually have no necessary following up with the schedule and effect of training, making enterprise managers not able to timely get the progress condition of training work. Therefore, when there exists problems in the training progress, managers also have no way to timely know what the problem is, so that they can't make the corresponding measures aiming at problems. Secondly, most enterprises in our country always adopt the method of unilateral assessment in the process of staff training assessment, namely, enterprise managers usually can get the satisfaction degree of staffs to training, but they will not have the thorough and detailed understanding with the actual effect produced by the training. In other words, the promotion of personal quality, work ability and attitude of staffs after the training can't be timely investigated and assessed, which will make the enterprise managers not able to understand the true condition and actual effect of training. So such assessment method is not favorable for managers to master the whole situation of enterprises, namely, they are blind with the effect of training. But as the manager of enterprises, they must have the ability to control the whole situation and master the development direction of enterprise, thus, the method of unilateral assessment is necessary to be perfected.

\section{The Construction of Staff Training System on the Basis of Knowledge Management}

\subsection{Change the training method}

Making analysis with the traditional training method of trainers teaching and the existing numerous problems, many schools have gradually implemented the new curriculum reform nowadays, making students the subjects of classes, while the teacher is just the instructor. The corresponding change that is favorable to the enterprise development also should be made in staff training in the enterprise. And in the progress of training, changing the staff not the trainer as the subject of training course, and the 
teacher is only the supplementary effect to help staffs understand. When the trainer is teaching the related training content, they can take staffs to experience by themselves. And in the training progress, they are supposed to encourage staffs to discuss and put forward questions, so that they can timely understand the master condition and existing problem of staffs to the training content. In addition, enterprise managers should allow staffs to come up with their suggestions with the training contents and objectives, encourage staffs to initiatively raise their own viewpoints and make adoption to make the corresponding adjustment aiming at the rational suggestions. And only by this way can staffs initiatively take part in the training work and positively master the knowledge. And this method can help training make more interesting and give full play to the effect it should have, rather than the stiff proceeding with the style of accomplishing task. All in all, in the aspect of staff training, enterprises should dare to innovate and positively introduce some excellent and referential foreign training method to perfect the existing disadvantages of itself, deliver more professional knowledge to staffs and make training method develop towards the more diversified direction. Because that the era that we are in is a era with rapid development and constant increasing of information and technology, so enterprises should adopt the method of connecting with information technology in the aspect of staff training, for example, new type audiovisual technology, which takes the training method of E-learning to make staffs initiatively study in the spare time of work and promote their professional skills. Enterprises also can classify with the training objectives, for example, according to the different work characteristic, they can be divided into skill training, knowledge training and attitude training. And skill training mainly means that the ability of staffs to use tools and solve problems. Knowledge training mainly means the exercise of mental activity, while attitude training mainly means the training aiming at the philosophy, value and professional ethics etc. Make specific training method with the different professionalism can make training produce actual effect rather than formalistic.

\subsection{Formulate rational contents and objectives of staff training}

When enterprises are formulating the contents and objectives of staff training, they should consider from the aspect of the long-term development and prosperity of enterprise at first, rather than only limited by the immediate benefit and making enterprises lose the possibility of long-term development due to making short small benefit. Next, staff training should focus on regarding the promotion of personal quality, work ability and attitude of staffs as crucial premise, rather than only regarding them as the machines to meet the benefit of enterprise, which will only make staffs lose the enthusiasm and initiative of work. And viewing from the development of enterprise, talents are key to the enterprise, and it is necessary to train excellent talents; when staffs lose the enthusiasm with work and constant promotion space, the enterprise is bound to be faced with the corresponding crises. What's more, in order to realize its long-term development, no matter in the aspect of human resource, material resource and financial resource, enterprises will make the necessary cost invest to do the work of market research and timely master the direction of social economy development, the demand of market development and personal development of staffs, so that the scientific and rational training contents and objectives that correspond with the long-term development of enterprises. And they are oriented with the training of talents who live up to the development direction of social economy and long-term development of enterprises, so that they can lay the good foundation for the long development of enterprises. The reason is that excellent staffs are the soul of enterprise and key people who put forward their solutions and solve the problems, which is the significant factor for enterprises to achieve its well development. Furthermore, enterprises should also carry out different training content with staffs of different positions and job function, adopt the corresponding training method according to their work characteristics and make the things that staffs are good at more optimized to realize the optimal training effect.

\subsection{Perfect the assessment system}

It is an essential part for training work to establish the assessment system, and it is the important method to test the final result of training. Therefore, enterprises should timely make the effective assessment with the result of staff training. In our country, although lots of enterprises have established their corresponding assessment system, it is not perfect and there exists deficiency in many aspects. So 
the existing deficiency must be made the comprehensive improvement in the assessment system. First of all, in the process of training, enterprise managers are supposed to follow with the schedule of training at any moment, master the progress of training and timely know the condition and existing problems in the process of training, in order to make the adjustment and adopt the reasonable measures in time. If enterprise managers cannot timely train but follow with their free development, and they don't make the effective supervision and assessment, then as for enterprises, they may be faced with the loss of human resource, material resource and financial resource, etc. Secondly, the corresponding accomplishment aiming at this assessment system should be made with the problems that many enterprises only have unilateral assessment system. Thus, they should pay attention to assessment with the actual effect produced by training rather the satisfaction degree of staffs to the training, which mainly expresses at the promotion of work ability, attitude and personal quality, as well as the sense of identity with enterprises, so that they can get the accurate and detailed understanding with the actual effect of training. If the satisfied or desired effect is not obtained, they should timely figure out the reason and make the corresponding adjustment, making sure that staffs can get perfect training and learn effective knowledge from the training. When the assessment system is more perfect, the effect of staff training is bound to better and better, so that enterprises will get better development.

\section{Conclusion}

In conclusion, along with the major change of social economy method, traditional management methods have been gradually eliminated, and knowledge management has been the important content of enterprise running and management day by day. The concept of knowledge management can help enterprises establish more scientific and rational staff training system. And aiming at the characteristics of era and economy development, enterprises should constantly understand more knowledge and the key point of knowledge management enterprise, perfect the management method of enterprises and take reasonable and specific training methods to promote the long-term development of enterprises and continuous enhancing of individual ability of staffs.

\section{References}

[1]. Wei Wang. The construction of training management system based on the staff growth[J]. Chinese labor, (3):39-41.

[2]. Qinghua Lang. The construction and analysis of institutional repository service system on the basis of knowledge management[J]. Information Studies: Theory \& Application, 2011,(9):64-67.

[3]. Wenbin Huang. The design of staff training system of XX bank on the basis of knowledge management[J]. Lanzhou University, 2014, (6):88-92. 